\title{
A ADAPTAÇÃO ESTRATÉGICA À GESTÃO AMBIENTAL EM UMA AGROINDÚSTRIA DO OESTE DE SANTA CATARINA
}

THE STRATEGIC ADAPTION TO ENVIRONMENTAL MANAGEMENT IN AN AGROINDUSTRY AT WESTERN OF SANTA CATARINA - BRAZIL

Rosiane Oswald Universidade do Vale do Itajaí -Univali - SC Faculdade de Itapiranga - FAI - SC rosiane.oswald@bol.com.br

Ivanete Schneider Hahn Universidade Federal de Santa Maria - UFSM - RS Universidade Alto Vale do Rio do Peixe - UNIARP - SC ivischneider@hotmail.com

Flávia Luciane Scherer Universidade Federal de Santa Maria - UFSM - RS

flaviascherer@globo.com

Lúcia Rejane da Rosa Gama Madruga Universidade Federal de Santa Maria - UFSM - RS lucia.rejane@hotmail.com

Marcleide Fischer Borsato Faculdade de Itapiranga - FAI - SC adm@seifai.edu.br

Marinete Schneider Rambo Faculdade de Itapiranga - FAI- SC marinete.s.rambo@seara.com.br

Submissão: $11 / 06 / 2013$

Aprovação: 05/03/2015 


\title{
RESUMO
}

As questões ambientais passam a receber maior atenção por parte dos gestores, uma vez que a sociedade passou a demandar das empresas uma postura responsável e sustentável. A finalidade deste estudo foi compreender e descrever o processo de adaptação estratégica, em relação à gestão ambiental, em uma agroindústria do oeste de Santa Catarina. A pesquisa caracteriza-se como descritiva e empregou um estudo de caso único e sua execução deu-se por meio de um estudo longitudinal seguindo o modelo proposto por Pettigrew (1987) que propõe verificar o cenário da mudança organizacional em três dimensões: o processo, o conteúdo e o contexto. Conclui-se que o processo de adaptação estratégica da empresa em estudo é mimético ao entendimento e evolução da gestão ambiental para os gestores.

Palavras-chave: Administração estratégica. Gestão ambiental. Agroindústria.

\begin{abstract}
The environmental issues emerge and receive more attention because the society starts to require a responsible and sustainable position from the companies. The purpose of this study was to comprehend the process of strategic adaptation, focusing on environmental management in an agroindustry on western the state of Santa Catarina in Brazil. The research is characterized as descriptive, studying a particular case, through a longitudinal study, using Pettigrew (1987) model, that proposes check the setting of organizational change in three dimensions: process, content and context. We concluded that the process of strategic adaptation at the company is proportional about the understanding and development of managers linked the environmental management.
\end{abstract}

Keywords: Strategic management. Environmental management. Agroindustry. 


\section{Introdução}

Ao longo do século XX, as empresas presenciaram o surgimento de um novo modelo de sociedade. Nesse momento o mercado voltou-se para a busca de melhorias na qualidade dos produtos oferecidos e para a procura constante da satisfação do cliente. Esse processo intensificou-se a partir dos anos 2000, e a sociedade, munida de informações, passou a cobrar um comprometimento maior das organizações no seu processo de produção, exigindo a redução de impactos ambientais, que pudessem ocorrer durante os processos produtivos.

Esse novo olhar exigiu das organizações adaptações em suas plantas e o uso de novas tecnologias de produção e de gestão, tecnologias limpas, um compromisso maior com a comunidade em torno da empresa, e uma corresponsabilidade com as questões ambientais eminentes que se apresentam. Consequentemente, as empresas ficaram sujeitas às exigências desta sociedade que passou a não aceitar mais o comportamento exclusivo de geração de riqueza sem a preocupação com o entorno da empresa. Surgem, então, as primeiras estratégias empresarias no sentido de adaptação aos apelos de essa nova geração conseguir passar a imagem de uma empresa responsável com a comunidade e com o mínimo de interferência no meio ambiente. Esta passagem de "empresa exploradora" para "empresa sustentável" (na perspectiva ambiental do termo) é geradora de questionamentos por não se ter clareza até onde vai o papel das organizações, uma vez que o modelo antigo adotado parecia insustentável ao longo dos anos (GUARNIERI et al., 2006).

As atividades industriais são o centro do desenvolvimento econômico. Em seus processos usam matérias-primas retiradas da natureza, transformam e alteram o estado físico de produtos, consequentemente geram resíduos, que, se não forem devidamente tratados, ocasionam diversos problemas que refletem na sociedade e em si próprios. As transformações das últimas décadas trazem novos conceitos de gestão para as organizações, provocando a necessidade de mudança no comportamento, aderindo ao contexto de desenvolvimento sustentável e responsável (CAMARA, 2009).

Rumo ao desenvolvimento sustentável, as questões ambientais passam necessariamente a fazer parte das políticas das indústrias. A associação das necessidades globais com a nova postura das empresas leva à necessidade de compreender que as despesas com a implantação da gestão ambiental não devem ser vistas como custo, mas como investimento em longo prazo, tornando-se um diferencial competitivo essencial para a 
sustentabilidade dos negócios, principalmente para as indústrias, por elas realizarem suas transações em mercados mais exigentes, como os internacionais (CARROLL, 1999).

A questão ambiental tem apontado a necessidade de adaptação das empresas, na garantia de seu desenvolvimento, para o que exige a quebra de paradigmas e mudanças de compreensão dos fenômenos, das estratégias e posicionamentos, no intuito de melhorar sua imagem e seus produtos, adaptando-se à nova realidade que busca produtos e empresas sustentáveis. Contudo, as pesquisas da área de gestão ambiental não têm enfocado o processo de adaptação estratégica das empresas, não havendo uma conclusão sobre por que algumas empresas do ramo utilizam estratégias resignadas, enquanto outras adotam uma postura defensiva ou ofensiva, ou ainda, qual a posição dos gestores neste processo.

A partir dessas lacunas surge a questão: de que forma ocorreu o processo de adaptação estratégica em relação à gestão ambiental, em uma agroindústria do oeste de Santa Catarina?

Este artigo divide-se em cinco partes, observando que esta primeira objetivou contextualizar os aspectos gerais do trabalho. Na segunda parte, apresenta-se a fundamentação teórica, expondo os principais conceitos e abordagens à estratégia e adaptação estratégica, evolução do conceito de gestão ambiental, contribuição da gestão ambiental para as organizações, as fases evolutivas da gestão ambiental nas organizações e um panorama sobre as publicações internacionais acerca do tema. A terceira seção apresenta a perspectiva metodológica do trabalho. Na quarta constam os principais resultados do trabalho. Por fim, apresentam-se as considerações sobre a pesquisa, limitações e sugestões de trabalhos futuros.

\section{A estratégia e a adaptação estratégica}

Não há uma conceituação simples para a estratégia. Mintzberg et al. (2006) apresentam vários aspectos, que influenciam na definição de uma estratégia, entre os quais citam-se: (1) planos, (2) pretextos, (3) padrão, (4) posição, (5) perspectiva e as inter-relações entre estes. Em suas colocações, o plano tem a pretensão de direcionar a organização com ações predeterminadas; as ações são preestabelecidas no planejamento; o pretexto é visto como o motivo para o uso de manobras para obtenção de vantagens; o padrão considera o comportamento da empresa; a posição é o posicionamento com intuito de evitar a competição; e a perspectiva refere-se a intenção e aspectos almejados. 
A formação de estratégias trata-se de um processo que envolve a missão, objetivos, metas, negócio, domínio de ação, políticas, diretrizes, normas e dados como quantidades, prazos e duração, e consiste em conciliar todas essas dimensões em seu planejamento (BETHLERM, 2008). A estratégia define os rumos de organização, levando em conta todas as dimensões existentes. Mintzberg et al. (2006, p. 39) sustentam que "estratégia é criar ajuste entre as atividades de uma empresa. O sucesso de uma estratégia depende de fazer bem várias coisas - e não apenas algumas - e da integração entre elas".

Observa-se que a estratégia está relacionada ao direcionamento em longo prazo da organização e ao escopo de suas atividades, definindo as responsabilidades e limites incluindo leque de produtos ou alcance geográfico, por exemplo. Para esses mesmos autores, as decisões estratégicas normalmente estão relacionadas à obtenção de vantagens em seu mercado de atuação, por meio do ajuste com o ambiente empresarial, com expansão geográfica, identificação de nichos de mercado ou aquisição de outras empresas, ou ainda com a criação de oportunidades explorando os recursos e competências disponíveis. Eles evidenciam ainda que a estratégia da organização é afetada não somente pelas forças ambientais, é influenciada também pelos valores e expectativas dos stakeholders (JOHNSON; SCHOLES; WHITTINGTON, 2007).

Porter (1999, p. 27) sustenta que "a essência da formulação estratégica consiste em enfrentar a competição”. No que se refere à questão ambiental, sua visão aborda a formulação da estratégia com enfoque para a competitividade, e defende a inovação em resposta a regulamentação ambiental sob duas categorias: a inovação com o uso de novas tecnologias que minimizam o custo do tratamento da poluição ou a inovação que ataca as causas básicas da poluição partindo da melhoria da produtividade dos recursos, utilizando materiais menos dispendiosos ou melhorando a utilização dos existentes. Porter (1999) acrescenta, sob o foco estratégico, que "a maneira como as empresas respondem aos problemas ambientais talvez seja, de fato, um indicador-chave da sua competitividade geral” (p. 396). Barbieri (2007, p. 126) corrobora explicando que por estratégia pode-se entender o "estabelecimento de objetivos e ações que alcancem efeito no ambiente de negócio em que a empresa atua ou pretende atuar, colocando-a numa posição de vantagem”.

Nesse cenário, surge o conceito de adaptação estratégica, que Gomes (2007) explica ser usado para abordar as mudanças ambientais relevantes e as adequações das organizações a tais mudanças, para a solução de possíveis problemas e situações emergentes, uma vez que, 
para consolidar sua existência e manter seu crescimento, as organizações precisam responder as mudanças em seu ambiente e adaptar suas estratégias, sem perder seu foco principal. Dessa forma, a adequação estratégica entre os processos é essencial para as empresas em busca de vantagem competitiva em longo prazo sobre os rivais (DRANOVE et al., 2006).

Posicionar-se estrategicamente significa estabelecer vantagem competitiva no mercado de atuação, com ações proativas, inovadoras e diferentes, no intuito de alavancar os negócios, destacando-se em suas atividades, o que parece representar um grande desafio às organizações hodiernas.

\section{Evolução do conceito de gestão ambiental}

A preocupação com o meio ambiente ganhou maior ênfase a partir dos anos 50, período em que surgiram movimentos ambientalistas e foram criadas organizações não governamentais sem fins lucrativos e agências governamentais voltadas para as questões ambientais, e a realização de conferências para discussão dos problemas ambientais. Na década de 1960, o livro Primavera Silenciosa, publicado por Raquel Carson, causou polêmica por expor os perigos do inseticida DDT. O livro teve repercussão global e despertou o interesse popular e gerencial para a questão ambiental. Nesse mesmo período surgiram legislações ambientais mais severas em todo o mundo, e até então a questão ambiental era vista apenas como geradora de custos para as empresas (ALPERSTEDT; QUINTELLA; SOUZA, 2010).

Ainda na década de 1960 foi divulgado o relatório "Os limites do crescimento" pelo Clube de Roma, com previsões pessimistas e alarmistas, que mais tarde foram consideradas errôneas, porém é reconhecido pelo fato de despertar e motivar para mudanças comportamentais em relação ao meio ambiente (MOURA, 2008). Em paralelo, Dias (2009) sustenta que no Brasil, a partir da década de 1960, houve a intensificação da industrialização e consequentemente dos impactos ao meio ambiente.

A Conferência das Nações Unidas, realizada em 1972 na cidade de Estocolmo, na Suécia, enfatizou a importância da educação ambiental para despertar a responsabilidade com relação ao uso racional dos recursos; resultaram deste evento a Declaração sobre o Ambiente Humano, um Plano de Ação Mundial, com a finalidade de nortear a preservação e melhoria 
do ambiente humano, e a criação do Programa das Nações Unidas sobre o Meio Ambiente (DIAS, 2009).

As mudanças na atitude industrial na década de 1980 foram confirmadas na propagação dos selos verdes na Europa, que eram primariamente baseadas na redução ou eliminação de poluentes de maior proporção do produto, ampliando-se para o processo de produção e descarte (ALPERSTEDT; QUINTELLA; SOUZA, 2010).

No Brasil a legislação ambiental tornou-se mais consistente a partir dos anos 1980, concretizando e estabelecendo uma combinação entre atividades das empresas e o meio ambiente, por meio da Constituição Federal de 1988, art. 225. Na década 1990, o tema consciência ambiental era predominante e merecedor de destaque, momento em que se começou a falar em qualidade ambiental e "muitas empresas passaram a se preocupar com a racionalização do uso de energia e de matérias-primas [...], além de existir um maior empenho na promoção da reciclagem e reutilização de materiais, evitando-se os desperdícios" (MOURA, 2008, p. 12).

Nesse período a questão ambiental passou a ser concebida de forma mais sistêmica e regrada, as organizações perceberam que os consumidores passaram a dar preferência para as empresas que trabalham valores ambientais em seu contexto (ALPERSTEDT; QUINTELLA; SOUZA, 2010).

A gestão ambiental começou a tomar forma, e sua evolução incluiu o conceito e os princípios de sustentabilidade nos aspectos administrativos e na estratégia. Viterbo Júnior (1998) já afirmava que a sobrevivência das organizações está estreitamente atrelada ao conceito de desenvolvimento sustentável, pois a sociedade, como um todo, não admite mais abusos ao meio ambiente, como aqueles causadas nas décadas passadas por empresas que não tinham essa preocupação.

O comportamento das empresas diante da nova realidade tem apresentado como opção para o alcance de vantagens competitivas diante do mercado, a conciliação dos âmbitos: econômico, social e ambiental (ELKINGTON, 2001), como pontos relevantes para a gestão. É acrescentada mais uma responsabilidade ao gestor: a definição de estratégias que considerem tais aspectos.

Nas organizações, de acordo com Alperstedt, Quintella e Souza (2010), a gestão ambiental é o elemento da função gerencial que aborda, decide e coloca em prática a política 
de meio ambiente instituída para a empresa, definindo os rumos práticos da empresa no que tange a responsabilidade ambiental em harmonia com os seus objetivos.

A integração da gestão ambiental à atividade de produção é perceptível por sua natureza transformadora de recursos, pois, da mesma forma como a ação do homem causa impacto no meio ambiente, também as empresas com suas atividades impactam, direta ou indiretamente (MARTINS, 2008). O mesmo autor relaciona quatro áreas de maior relevância: água, energia, recursos naturais - matérias-primas extraídas da natureza - e a geração de resíduos.

A gestão ambiental é muito ampla, por envolver a empresa no seu ambiente interno e também na sua relação com os fatores e determinações externas, exigindo visão holística e flexibilidade, para adaptar-se. Essa amplitude é confirmada Seiffert (2007, p. 24), ao afirmar que a gestão ambiental é entendida como um processo adaptativo e contínuo, em que as organizações definem e redefinem seus objetivos e metas relacionadas à proteção do meio ambiente, à saúde de seus empregados, bem como de clientes e comunidade, além de selecionar estratégias e meios para atingir esses objetivos num tempo determinado, por meio da constante avaliação de sua interação com o meio externo.

\section{Contribuição da gestão ambiental para as organizações}

De acordo com Barbieri (2007), a solução dos problemas ambientais, ou minimização desses, demanda uma atitude inovadora dos empresários e administradores, que devem levar em consideração o meio ambiente em suas decisões e adotar princípios que garantam a sustentabilidade para o planeta.

Dias (2009) corrobora que compete à empresa reconhecer que está inserida na sociedade, que dela depende, pois nela estão seus consumidores e fornecedores, e que está condicionada a cumprir seu papel de integração com as políticas, programas e métodos ambientais em todos os negócios como elementos imprescindíveis de administração em todos seus comportamentos. O mesmo autor comenta que há diversas vantagens e benefícios que as empresas podem auferir ao adotar políticas preventivas em relação à gestão ambiental.

Donaire (2008) relaciona os principais benefícios econômicos e estratégicos na adoção da gestão ambiental preventiva. Os benefícios econômicos referem-se a economia de custos seja pela redução do consumo de água, energia e insumos, reciclagem ou reaproveitamento de 
resíduos, diminuição de efluentes, ou por redução de multas e penalidades por poluição - e incremento nas receitas - por meio do aumento da contribuição dos produtos verdes (que podem ser vendidos por preços mais altos), aumento na participação de mercado devido a inovação dos produtos e menos concorrência, ou pelo aumento na demanda por produtos menos poluentes.

Já os benefícios estratégicos referem-se a melhoria da imagem institucional, renovação do portfólio de produtos, aumento da produtividade, alto comprometimento do pessoal, melhoria das relações de trabalho, criatividade para novos desafios, melhores relações com os órgãos governamentais, comunidade e ambientalistas, acesso assegurado ao mercado externo e melhor adequação aos padrões ambientais (DONAIRE, 2008).

Por fim, Alperstedt, Quintella e Souza (2010) sustentam que a opção por medidas ambientalmente responsáveis por parte das empresas é motivada por razões internas e externas. Internamente a empresa beneficia-se com a redução dos custos, otimiza os processos produtivos, inovações tecnológicas e melhora da imagem, e previne acidentes ecológicos. Dessa forma, agrada a sociedade composta pela comunidade local, governo, organizações e agências financiadoras (razões externas).

\section{Fases evolutivas da gestão ambiental nas empresas}

A variável ecológica desempenha sua influência na estratégia das organizações, de forma que exige que sejam feitas alterações em algum momento, seja para atender a uma nova lei, seja por iniciativa antecipando-se ao que possa ocorrer no futuro. Nesta seção, são abordados os modelos que servirão para análise do processo de adaptação estratégica em relação à gestão ambiental do caso em estudo.

Winsemius e Guntran (2004) classificam as respostas das empresas em relação às questões ambientais como: reativas, funcionais, integradas e proativas. Os mesmos autores explanam que as reativas ocorrem quando as empresas prendem-se a cumprir meramente o que é imposto pela legislação, relutam e sentem-se injustiçadas a cada nova lei que surge e que lhes é imposta; as funcionais ocorrem quando as empresas assumem suas responsabilidades gradativamente à medida que vai surgindo a legislação; nas integradas, as empresas procuram conciliar e integrar as suas estratégias negociais com os interesses da sociedade, do governo e das ONGs, estabelecendo parcerias; e quanto às proativas, os autores 
classificam-nas como a administração do futuro, por exigir mudanças profundas nas organizações, e sugerem a valorização das ações das empresas em perfeita harmonia como o meio ambiente.

Para Barbieri (2007), a empresa pode desenvolver três enfoques denominados como: (1) o controle da poluição, (2) a prevenção da poluição e (3) incorporação dessas questões na estratégia empresarial. O mesmo autor complementa que o controle da poluição é caracterizado por ações que visam impedir os efeitos da poluição em um determinado processo de produção, para tanto concentram sua atenção nos aspectos negativos dos produtos ou dos processos produtivos e em atender a legislação vigente, sem muitos investimentos em tecnologias. Já a prevenção da poluição condiz com uma produção mais eficiente, com a redução do uso de materiais e energia por meio de mudanças nos processos produtivos, na expectativa da redução dos custos de produção, dos resíduos e dos passivos ambientais e consequente melhoria da produtividade, das condições de trabalho e da imagem da empresa. A abordagem estratégica é relacionada ao posicionamento que a empresa busca no mercado, na atmosfera de negócios, junto aos fornecedores, consumidores e opinião pública, buscada através da divulgação e apresentação de suas ações.

Somada a essa abordagem, diversos autores descrevem suas concepções sobre estratégias e as respostas das empresas às pressões ambientais. Essas abordagens são apresentadas, de forma sintetizada, no Quadro 1.

Quadro 1 - Principais tipologias em relação às formas de pressões de estratégias ambientais

\begin{tabular}{|c|c|c|}
\hline Autor & Principais estratégias & Significado em relação às estratégias ambientais \\
\hline $\begin{array}{l}\text { Baumol e Oates } \\
(1979)\end{array}$ & Estratégia reativa & $\begin{array}{l}\text { Valoriza a maximização da geração de lucros no menor prazo. } \\
\text { As questões ambientais não são bem aceitas. }\end{array}$ \\
\hline Tomer (1992) & $\begin{array}{l}\text { Preocupação com a ética } \\
\text { ambiental }\end{array}$ & $\begin{array}{l}\text { Nesse pensamento as questões relacionadas à ética ambiental e } \\
\text { ao envolvimento com a sociedade devem fazer parte das ações } \\
\text { diárias da organização. }\end{array}$ \\
\hline \multirow{3}{*}{ Meredith (1995) } & $\begin{array}{l}\text { Tipologia ambiental } \\
\text { reativa }\end{array}$ & $\begin{array}{l}\text { Caracteriza-se por atender o mínimo obrigatório na legislação. } \\
\text { Não promove mudanças nos processos e nos produtos. } \\
\text { Controla somente a emissão da poluição. }\end{array}$ \\
\hline & $\begin{array}{l}\text { Tipologia ambiental } \\
\text { intermediária }\end{array}$ & $\begin{array}{l}\text { Acata o uso consciente dos recursos naturais e promove a } \\
\text { redução da poluição. Vai além do obrigatório e consegue } \\
\text { antecipar ações antes dos concorrentes. }\end{array}$ \\
\hline & $\begin{array}{r}\text { Tipologia } \\
\text { inov }\end{array}$ & $\begin{array}{l}\text { Ocorre a gestão ambiental estratégica. Ações proativas antes da } \\
\text { geração do problema ambiental. }\end{array}$ \\
\hline \multirow[b]{2}{*}{$\begin{array}{l}\text { Rondinelli e } \\
\text { Vastag (1996) }\end{array}$} & $\begin{array}{l}\text { Tipologia ambiental } \\
\text { reativa }\end{array}$ & $\begin{array}{l}\text { Apresenta reduzida emissão de gases poluentes, de baixo nível } \\
\text { de periculosidade. }\end{array}$ \\
\hline & $\begin{array}{l}\text { Tipologia ambiental } \\
\text { proativa }\end{array}$ & $\begin{array}{l}\text { Pelas condições climáticas e pela localização, não são } \\
\text { avaliadas como consequências graves para esta forma de } \\
\text { poluente. }\end{array}$ \\
\hline
\end{tabular}




\begin{tabular}{|c|c|c|}
\hline & $\begin{array}{l}\text { Tipologia ambiental } \\
\text { estratégica }\end{array}$ & $\begin{array}{l}\text { As questões ambientais são fundamentais no momento de } \\
\text { decisão estratégica. }\end{array}$ \\
\hline & $\begin{array}{l}\text { Tipologia ambiental de } \\
\text { prevenção às crises }\end{array}$ & $\begin{array}{l}\text { As formas de poluição não ocorrem diretamente e as } \\
\text { consequências para a população não são significativas. }\end{array}$ \\
\hline \multirow{4}{*}{$\begin{array}{l}\text { Azzone } \text { et al. } \\
\qquad(1997)\end{array}$} & $\begin{array}{l}\text { Tipologia ambiental } \\
\text { lobista/passiva }\end{array}$ & $\begin{array}{l}\text { As questões ambientais são vistas como reducionistas da } \\
\text { competitividade. Menor investimento possível na área } \\
\text { ambiental. }\end{array}$ \\
\hline & $\begin{array}{l}\text { Tipologia ambiental } \\
\text { reativa }\end{array}$ & $\begin{array}{l}\text { As ações normalmente são tomadas quando pressionados pelos } \\
\text { "stakeholders", foco na competitividade. }\end{array}$ \\
\hline & $\begin{array}{l}\text { Tipologia ambiental } \\
\text { "verde" antecipada }\end{array}$ & $\begin{array}{l}\text { Foco nas mudanças contínuas em relação às melhorias } \\
\text { ambientais, procurando antever a legislação. }\end{array}$ \\
\hline & $\begin{array}{l}\text { Tipologia ambiental } \\
\text { verde orientada à } \\
\text { inovação }\end{array}$ & $\begin{array}{l}\text { Investimentos em redução dos impactos causados nos } \\
\text { processos e formulação dos produtos. Recursos disponíveis } \\
\text { para inovação. }\end{array}$ \\
\hline \multirow{4}{*}{$\begin{array}{l}\text { Brockhoff e } \\
\text { Chakrabarti } \\
\text { (1999) }\end{array}$} & $\begin{array}{l}\text { Tipologia ambiental } \\
\text { defensora de Portfólio }\end{array}$ & $\begin{array}{l}\text { Procura manter-se informada quanto às novas regulamentações } \\
\text { legais para se anteceder à legislação. }\end{array}$ \\
\hline & $\begin{array}{l}\text { Tipologia ambiental } \\
\text { escapistas }\end{array}$ & $\begin{array}{l}\text { Prefere abandonar mercados a fazer muitos investimentos } \\
\text { ambientais. Não valoriza a antecipação das normas legislativas. }\end{array}$ \\
\hline & $\begin{array}{l}\text { Tipologias ambientais } \\
\text { inativas ou indiferentes }\end{array}$ & $\begin{array}{l}\text { Embora tenham uma política ambiental clara, não demonstram } \\
\text { fazer uso delas. Normalmente abrangem baixo risco ambiental. }\end{array}$ \\
\hline & $\begin{array}{l}\text { Tipologia ambiental } \\
\text { ativista }\end{array}$ & $\begin{array}{l}\text { Valorização da exploração de novos mercados, por isso dá-se } \\
\text { grande importância em atender e antecipar inovações } \\
\text { ambientais. }\end{array}$ \\
\hline \multirow{4}{*}{$\begin{array}{l}\text { Winn e Angell } \\
\quad(2000)\end{array}$} & $\begin{array}{l}\text { Greening deliberado } \\
\text { reativo }\end{array}$ & $\begin{array}{l}\text { A direção não demonstra dar importância às questões } \\
\text { ambientais. }\end{array}$ \\
\hline & $\begin{array}{l}\text { Greening deliberado } \\
\text { proativo }\end{array}$ & $\begin{array}{l}\text { Comprometimento da direção administrativa com a } \\
\text { sustentabilidade do negócio. Investimentos altos em melhorias. }\end{array}$ \\
\hline & Greening não realizado & $\begin{array}{l}\text { Apresenta compromisso forte com as políticas ambientais e } \\
\text { leva em consideração o meio ambiente em todas as decisões } \\
\text { funcionais. }\end{array}$ \\
\hline & Greening ativo & $\begin{array}{l}\text { As questões ambientais não são consideradas em todas as ações } \\
\text { funcionais. }\end{array}$ \\
\hline
\end{tabular}

Fonte: Adaptado de Cunha (2008).

São amplas as ações envolvendo as questões ambientais, variando desde uma inércia de algumas organizações ao comprometimento efetivo de outras. Outro aspecto que pode ser observado é uma evolução cultural e de inciativas das organizações ao longo do tempo de existência, procurando adaptar-se aos novos conceitos ambientais e estratégicos.

\section{Panorama das publicações internacionais em relação à adaptação estratégica}

A gestão ambiental é um tema discutido em vasta literatura, contudo seu consórcio com a adaptação estratégica ainda não reflete os mesmos resultados. Nessa perspectiva, optou-se por fazer um levantamento do panorama das publicações internacionais em relação à adaptação estratégica e gestão ambiental. 
$\mathrm{Na}$ primeira etapa da pesquisa inseriu-se as palavras strategic adaption (adaptação estratégica) e environmental (meio ambiente) na plataforma Web of Science. ${ }^{1}$ Como resultados, sem inserir filtros de áreas e nem de data de publicação, foram encontradas cinco publicações, as quais se apresentam divididas em três artigos científicos, um material editorial e um proceeding paper.

Os autores que publicaram sobre o tema são: Moore e Kraatz (2011); Virvilaite, Seinauskiene e Sestokiene (2011); Baldo et al. (2009); Tao (2009) e Virany, Tushman e Romanelli (1992). Esses autores pertencem a Escolas dos Estados Unidos, Itália, Lituânia, China e Suécia, a saber: Columbia University, Duke University, Kaunas University of Technology, China University Technology e University of Illinois e das empresas Semco e Studio LCE. Apresentam-se, no Quadro 2, as principais contribuições dos trabalhos referenciados.

Quadro 2 - Principais contribuições dos estudos do levantamento bibliométrico

\begin{tabular}{|c|l|}
\hline Autores & \multicolumn{1}{|c|}{ Contribuições } \\
\hline Moore e Kraatz (2011) & $\begin{array}{l}\text { Seu artigo explora a forma como a governança afeta a capacidade de } \\
\text { adaptação das organizações - usando o caso das Savings and Loan (S\&L) } \\
\text { nos anos 1980. Os autores sugerem que as funções básicas do governo } \\
\text { são o estabelecimento do propósito organizacional e controle das } \\
\text { empresas. Destarte, a governança teria o poder de influenciar no processo } \\
\text { de adaptação estratégica das empresas. Os resultados sugerem que a } \\
\text { governança mútua é um recurso que permite as S\&L equilíbrio em face } \\
\text { de um ambiente de mudança. }\end{array}$ \\
\hline Virvilaite, Seinauskiene e & $\begin{array}{l}\text { Os autores propõem estudar a existência de alguma ligação entre a } \\
\text { padronização e adaptação estratégica nas decisões da estratégia de } \\
\text { marketing internacional e no desempenho da empresa. Apresentam um } \\
\text { modelo teórico que liga a padronização à adaptação estratégica. } \\
\text { O modelo revela que o desempenho da empresa pode não ser apenas o } \\
\text { resultado de padronização e adaptação de decisões, mas em relação aos } \\
\text { antecedentes dessas decisões. } \\
\text { Usando esse modelo, numa análise empírica, os resultados revelaram que } \\
\text { a padronização e a adaptação aliadas à liderança de custo e diferenciação } \\
\text { das estratégias, quando ajustadas, complementam-se. O caso nega } \\
\text { parcialmente os pressupostos teóricos de que a adaptação é compatível } \\
\text { com a estratégia de diferenciação e a padronização é compatível com a } \\
\text { estratégia de liderança de custo, e este revela que outras combinações de } \\
\text { decisões estratégicas também são possíveis, condicionando a melhoria do } \\
\text { desempenho da empresa. }\end{array}$ \\
\hline
\end{tabular}

${ }^{1}$ A Web of Science é a designação dada a um conjunto de bases de dados também conhecidas como Science Citation Indexes (Science Citation Index, Social Science Citation Index, Arts and Humanities Citation Index), compiladas pelo ISI (Institute for Scientific Information). Esta ferramenta permite, além da pesquisa habitual por ocorrência de palavras no registo, também a pesquisa de artigos relacionados e o estabelecimento de ligações entre artigos que citam outros ou são citados por outros. 


\begin{tabular}{|c|c|}
\hline Baldo et al. (2009) & $\begin{array}{l}\text { Os autores descrevem os resultados de um projeto para a European } \\
\text { Commission que objetivou desenvolver e verificar um software de } \\
\text { cálculo de emissão de carbono para a inclusão da questão das emissões } \\
\text { de GHG nos critérios de rótulo ecológico da União Europeia. } \\
\text { Os autores sugerem que um esquema do processo de decisão deve ser } \\
\text { feito durante a revisão dos critérios de atribuição do rótulo ecológico para } \\
\text { avaliar a possível inclusão de um critério sobre a pegada de carbono. }\end{array}$ \\
\hline Tao (2009) & $\begin{array}{l}\text { O autor apresenta o desafio dos gerentes de produção em encontrar } \\
\text { maneiras de lidar com a incerteza ambiental e aumentar a variedade de } \\
\text { produtos por meio de customização em massa, sem afetar prazo de } \\
\text { entrega, custo ou qualidade. Com base em dados coletados de } 204 \\
\text { empresas industriais, o estudo investiga as capacidades estratégicas } \\
\text { (capacidade de velocidade, capacidade de adaptação, capacidade de } \\
\text { inovação e capacidade de aprendizagem) que permitem às empresas } \\
\text { realizar a customização em massa. Os resultados mostram que a } \\
\text { capacidade de velocidade, capacidade de inovação e capacidade de } \\
\text { aprendizagem têm um impacto positivo sobre a customização em massa, } \\
\text { enquanto a capacidade de adaptação não tem nenhuma relação com a } \\
\text { customização em massa. }\end{array}$ \\
\hline $\begin{array}{l}\text { Virany, Tushman e Romanelli } \\
\text { (1992) }\end{array}$ & $\begin{array}{l}\text { O artigo explora a sucessão de executivos como um mecanismo para a } \\
\text { aprendizagem da organização e para a adaptação da organização. Os } \\
\text { resultados indicam que a sucessão exerce uma influência positiva sobre o } \\
\text { desempenho da organização. Apresentam que o impacto positivo da } \\
\text { sucessão é acentuado quando coincide com a reorientação estratégica. } \\
\text { Finalmente, os autores expõem dois modos de adaptação de empresas de } \\
\text { microcomputadores: 1) o modo mais típico que combina sucessão do } \\
\text { CEO, tirando o executivo da equipe de alterações e das reorientações } \\
\text { estratégicas; e 2) a mais rara e, em longo prazo, de modo mais eficaz, } \\
\text { gestão adaptativa que envolve reorientação estratégica e o executivo na } \\
\text { equipe de mudança, mas há sucessão do CEO. }\end{array}$ \\
\hline
\end{tabular}

Fonte: Elaborado pelas autoras (2013).

As publicações estão relacionadas às áreas de Business Economics (Economia Empresarial), Computer Science (Ciências da Computação), Engineering (Engenharia) e Environmental Sciences Ecology (Ciências Ambientais Ecológicas), estando publicadas nos seguintes Journals (revistas): Organization Science (com duas publicações), International Conference on Electronic Commerce and Business Inteligence Proceedings, International Journal of Life Cycle Assessment e Inzinerine Ekonomika Engineering Economics, com uma publicação cada revista.

Como se pode observar, as pesquisas na área são recentes e muito insipientes, havendo enfoque na adaptação estratégica geral das organizações, inferindo uma grande lacuna de estudos na área de adaptação estratégica em relação aos eventos ambientais. 


\section{Método}

Este estudo é caracterizado como qualitativo e descritivo. Sua operacionalização aconteceu por meio de um estudo longitudinal, que Hoffman (1999) explica como a busca por avaliar a evolução dos eventos, chamados de eventos de transição, por fazerem a transição de um período para outro.

A estratégia de pesquisa foi um estudo de caso único, que teve como delimitação o estudo da adaptação de uma agroindústria localizada no oeste do Estado de Santa Catarina aos eventos ambientais ocorridos na história da empresa. Para a coleta dos dados primários utilizaram-se as entrevistas semiestruturadas e pesquisa documental (documentos organizacionais, regulamentações legais). O estudo objetivou procurar os acontecimentos dispostos ao longo do tempo de vida da empresa. Para que isso fosse possível, realizou-se um levantamento histórico dos principais eventos ambientais da organização, desde sua origem.

O critério de seleção dos entrevistados foi o método de amostragem não probabilística, intencional, por conveniência. Assim foram entrevistados 4 (quatro) profissionais, gestores principais em seus setores. Em relação à comunidade, entrevistou-se uma pessoa que reside há muitos anos ao lado da empresa.

O roteiro da entrevista foi baseado na revisão da literatura. $\mathrm{O}$ tratamento dos dados ocorreu por meio das informações obtidas, que serviram de elementos para formular os principais eventos cronológicos, dividir esses eventos em datas e posteriormente caracterizálos, procurando retratar as adaptações estratégicas em relação às questões ambientais, ocorridas na organização, ao longo de sua existência.

Em relação à análise dos dados, as informações levantadas foram esquematizadas conforme o modelo proposto por Pettigrew (1987), assim, agruparam-se, de forma cronológica, os eventos por anos e, após, realizou-se a análise do processo, conteúdo e contexto. Para o mesmo autor, os eventos não podem ser tratados como acontecimentos, que ocorrem de forma isolada ou que não tivessem ligação com seus antecedentes, que lhe deram formato, definição e conteúdo. 


\subsection{Caracterização da empresa}

A empresa em estudo situa-se no extremo oeste catarinense. Atua no segmento de frigorífico de suínos, fazendo abate e desossa, possuindo habilitação junto ao Ministério da Agricultura brasileiro para abater e desossar 2.000 suínos por dia. Atua no mercado interno e externo com a venda de produto in natura, sendo os principais destinos estrangeiros de seus produtos países como Argentina, Chile e China. Busca constantes melhorias em sua estrutura física para possibilitar a entrada da empresa em mercados externos, como os Estados Unidos e Rússia.

Possui aproximadamente 600 funcionários, divididos entre os setores de desossa, abate, padronização e embalagem, recebimento, expedição, higienização, beneficiamento de tripas, fábrica de farinhas e ossos, administrativo e setores de apoio à produção, entre os quais podemos destacar os setores de manutenção, segurança no trabalho e garantia da qualidade. A empresa possui implantados diversos programas de qualidade.

\section{Eventos e períodos do processo de adaptação estratégica}

Cunha (2008) explana que, de forma geral, as empresas do setor industrial estão à frente na busca e na implementação de sistemas ambientais capazes de melhorar os processos de produção que minimizem tais riscos. Desse modo, neste item estão descritos os principais eventos e ações da agroindústria, que envolvem o processo histórico e a gestão ambiental, desde a sua implantação até 2013. As informações foram levantadas em contatos, entrevistas, documentos, jornais regionais e no site da empresa. A Tabela 1 apresenta e sintetiza os eventos em ordem cronológica.

Tabela 1 - Caracterização do período

\begin{tabular}{cc}
\hline ANO & AÇÃO DA EMPRESA \\
\hline 1997 & Inauguração \\
\hline 1999 & Paralização das atividades \\
\hline 2001 & Mudança da administração e retomada das atividades \\
\hline 2001 & Ampliação da área construída \\
\hline 2001 & Aumento da produção \\
\hline 2001 & Aumento da área territorial (aquisição de terra) \\
\hline 2001 & ETE - Estação de Tratamento de Efluentes (I) \\
\hline 2003 & Paralização das atividades \\
\hline
\end{tabular}




\begin{tabular}{cc}
\hline 2004 & Mudança administrativa \\
\hline 2004 & Ampliação e melhoria nas instalações \\
\hline 2004 & ETE - sistema de flotação e anaeróbico \\
\hline 2004 & Aumento da produção \\
\hline 2004 & Gestão do consumo de água \\
\hline 2004 & Compostagem orgânica \\
\hline 2006 & Projeto da coleta seletiva \\
\hline 2007 & Reciclagem dos resíduos sólidos \\
\hline 2007 & Ciclone úmido \\
\hline 2007 & ETE - Construção de mais quatro lagoas \\
\hline 2008 & Aumento da produção \\
\hline 2009 & ETA - Estação de tratamento de água \\
\hline 2009 & Construção da Fábrica de Farinha \\
\hline 2009 & Implantação do Programa de Educação Ambiental
\end{tabular}

Fonte: Elaborado pelas autoras (2013).

Embora existam poucos registros e informações do período inicial da empresa, tem-se uma percepção de que o empreendimento é fruto de um 'sonho', que, apesar de implantado em uma fase em que os princípios administrativos e a gestão ambiental estavam no auge das discussões, não se nota sua relevância no processo. O fundador da empresa, após aposentarse, idealizou a construção de um frigorífico de suínos e gado para o município. Após uma viagem à Europa, iniciou a construção, segundo a entrevistada (C): “[...] foram pra Alemanha e lá eles viram que tinha muito mercado né de suínos e de gado, pra eles poderem vender, daí depois ele começou a construção".

Em 1997, a agroindústria funcionou parcialmente, abatendo apenas suínos. A empresa manteve-se em atividade por dois anos, porém em 1999 as atividades foram paralisadas, por dificuldades de colocação dos produtos no mercado. No ano seguinte, 2000, as instalações da empresa foram locadas por outra empresa, mas as atividades não alavancaram, de modo que, neste mesmo ano, foi decretada a falência do empreendimento.

Em 2001, após negociações, as instalações foram adquiridas por outra empresa, que fez investimentos em obras de melhoria e ampliação na estrutura da planta, situação também versada pela entrevistada $(\mathrm{C})$ : “daí eles aumentaram bastante, investiram muito”. As obras de melhoria e ampliação de fato podem ser confirmadas pela descrição da pessoa envolvida no processo naquele período, ora identificado como entrevistado (D):

[...] o Frigorífico foi totalmente remodelado, pois a capacidade de abate era de 30 suínos/dia e 10 bovinos/dia, passou para 500 suínos/dia e foi desativada a parte do abate de bovinos [...]. A estrutura foi totalmente alterada e ampliada, desde o abate até a expedição. 
Percebe-se neste processo uma adaptação estratégica com o aumento da estrutura e da produção, ocasionando o aumento da demanda ambiental, obrigando a empresa a tomar as medidas de adequação envolvendo as questões ambientais:

[...] contratamos uma empresa de Chapecó para elaborar o projeto técnico e o acompanhamento do projeto nas questões ambientais, pois houve a necessidade de adquirir novas áreas de terra para fazer as lagoas e todo o processo de tratamento dos dejetos. No início tivemos muita dificuldade até conseguir tratar os dejetos de forma adequada e em níveis aceitáveis para largar no arroio [...], pois atingia diretamente alguns produtores que se abasteciam da água deste arroio para os animais. (ENTREVISTADO (D))

Observa-se que nesta fase foi implantado um sistema responsável pelo tratamento dos efluentes, e outro para o tratamento dos dejetos. Embora houvesse um planejamento estratégico, as questões ambientais não estavam inclusas a princípio, sendo consideradas apenas quando havia exigências legais:

Havia um planejamento estratégico, mas a necessidade de planejar mais as questões ambientais surgiram depois, pois no início foram observadas apenas as exigências legais e mais tarde se percebeu da necessidade de investir em áreas de terra para reflorestamento e recuperação ou compensação ambiental. (ENTREVISTADO (D))

O empreendimento tem um histórico de muitas alterações em sua composição societária, isso, somado aos períodos em que as atividades permaneceram paralisadas, acarretou um retardo de seu crescimento, pois a cada mudança ocorrida em seu contrato social havia mudanças culturais e políticas na empresa.

Em 2003 as atividades foram assoladas por uma crise e novamente paralisadas. Em 2004 as instalações foram negociadas e vendidas para outra composição societária, que retomou as atividades após investimentos na planta da fábrica, adequações para exportação, havendo um aumento da capacidade produtiva neste mesmo ano.

A partir desse período percebe-se um aumento de ações voltadas para as questões ambientais. Até 2004 a estação de tratamento de efluentes contava com duas lagoas - uma de 3,3 mil metros quadrados e outra de 1,6 mil metros quadrados - responsáveis pelo tratamento do efluente oriundo de um abate de 400 animais por semana. Durante este mesmo ano, após ampliação da planta industrial, houve um aumento de produção, passando de 400 animais abatidos por semana para 400 animais por dia. Em função deste aumento produtivo, foi 
implantado no sistema de tratamento de efluentes o processo de flotação e uma peneira estática, que consiste em separar e filtrar os resíduos sólidos.

Analisando o cenário descrito, nota-se que desde 2004 é realizada a gestão do consumo de água, por se tratar de recurso natural imprescindível no processo produtivo. A gestão do consumo da água incide na utilização racional e na otimização do seu uso em todas as operações da unidade, para tal são feitos acompanhamentos de controle e colocação de metas de redução, condição mencionada pela entrevistada (A): "então a gente tem um controle semanal, controle diário de alguns indicadores, controle mensal de outros indicadores, então, é feito e já tá nosso estratégico a gente tem que atingir $2 \%$ de redução no consumo de água por mês".

Ainda no ano de 2004 foi iniciada a compostagem dos dejetos, o que possibilitou o seu reaproveitamento dentro da própria unidade, usado como adubo para plantas, árvores e consequente embelezamento dos jardins, situação confirmada pela entrevistada (A). Foi implantado neste período, na primeira lagoa da estação de tratamento de efluentes, o sistema anaeróbico que consiste na eliminação de gordura do efluente com o uso de bactérias. As ações deste período na unidade, como o aumento de produção, ampliação da indústria e melhoramentos feitos na estação de tratamento, foram realizadas com o intuito estratégico de possibilitar o início das exportações.

No ano de 2006 a unidade iniciou um projeto de coleta seletiva de lixo com o objetivo de conscientizar os funcionários e todos envolvidos nos processos, da responsabilidade pelos resíduos que geram. A separação dos resíduos é realizada por meio de lixeiras devidamente identificadas. Até 2006, a produção permaneceu inalterada; foi a partir de 2007 que houve um aumento expressivo passando de 400 animais abatidos por dia para 1600 animais por dia, número contabilizado no início de 2008.

Ainda em 2007, a estação de tratamento de efluentes foi ampliada, passando de duas lagoas para um total de seis lagoas, devido ao aumento da demanda consequente do aumento produtivo. Houve neste ano mais uma ampliação na planta da indústria, de modo que a produção continuou aumentando. Da mesma forma, a unidade industrial passou a integrar um grupo reconhecido a nível mundial, passando a incorporar os valores, visão e missão do grupo. Pode-se ressaltar uma exigência importante que os acionistas fizeram para a unidade, a qual consistiu em que a estação de tratamento de efluentes atendesse aos parâmetros do Banco Mundial, o qual exige que os índices relacionados às questões socioambientais sejam 
atendidos para possibilitar a obtenção de empréstimos. Nessa fase, nota-se que a unidade passa por um processo de adaptações a nova cultura organizacional, com imposição dos valores e das estratégias corporativas.

A partir de 2009, com a construção da fábrica de farinha, o frigorífico começou a processar os resíduos sólidos, que antes eram vendidos e coletados por outra empresa. Do processamento destes resíduos resultam dois produtos - a farinha e o óleo - que são vendidos para fábricas de ração. O objetivo do investimento foi o aumento da receita, pois, pelo resíduo não processado, a empresa recebia em torno de $\mathrm{R} \$ 0,10$ por quilo, ao passo que pela farinha e o óleo recebem em torno de $\mathrm{R} \$ 1,50$ e $\mathrm{R} \$ 0,50$ por quilo, respectivamente. Porém, com o processamento dos resíduos, aumentou a quantidade de efluente a ser tratada; a solução dada foi a troca das bactérias utilizadas na estação de tratamento do efluente, para melhorar o processo.

Também em 2009, foi construída a estação de tratamento de água, própria da unidade, em função do alto consumo e da importância desse recurso nos processos produtivos. A unidade consome diariamente em torno de um milhão de litros de água, viabilizando o tratamento próprio, conforme afirma a entrevistada (A): "a água em si é um recurso natural caro, e como aqui a gente gasta em média 1 milhão de litros de água por dia, então isso tava se tornando um custo muito alto pra unidade". No mesmo ano, foi implantado o Programa de Educação Ambiental, que consiste no trabalho de retomada da consciência ambiental junto à comunidade. No programa foram envolvidos os estudantes do ensino médio e ministradas palestras sobre a importância da água, também foram oportunizadas visitas para que conhecessem os trabalhos realizados na empresa, demostrando que a água pode ser tratada e reutilizada.

O grupo empresarial no qual a unidade industrial está inserida atualmente adota ações e políticas condizentes com os princípios da responsabilidade ambiental no intuito de garantir a sustentabilidade de seus negócios em longo prazo. Para isso, cada uma das unidades pertencentes ao grupo desenvolve ações de acordo com suas peculiaridades operacionais locais que, em conjunto, garantem e contribuem para a sustentabilidade de todo o sistema produtivo. 


\section{Análise do processo, contexto e conteúdo das mudanças}

Os resultados descritos no item anterior serviram de base para analisar os fatores relacionados ao processo, contexto e conteúdo da mudança. Para tal, o tempo de existência da empresa foi dividido em dois grandes períodos, incluindo as ações e os eventos observados e mensurados por meio da pesquisa. O primeiro período compreende o tempo decorrido de 1997 a 2003, e o segundo de 2004 a 2010.

Tabela 2 - Caracterização dos períodos quanto à literatura

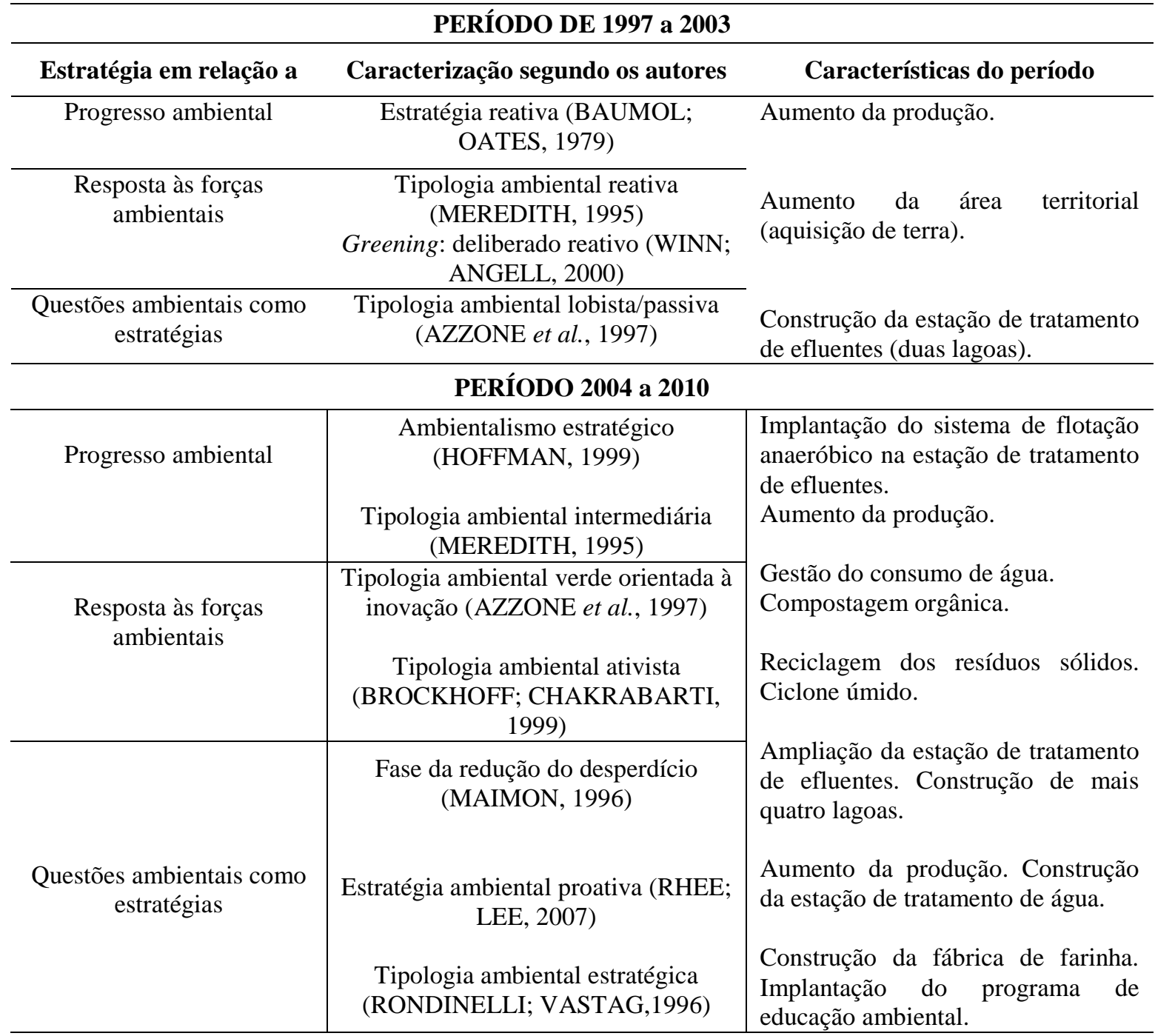

Fonte: Elaborado pelas autoras (2013).

Analisando as relações existentes entre o comportamento organizacional e o posicionamento da empresa quanto à literatura, percebe-se que houve uma evolução da 
empresa, no que se refere à variável ambiental, e que ao longo do período procurou adaptar-se de forma a consolidar e manter seu crescimento, alinhando suas estratégias incluindo esta variável na formulação do planejamento estratégico.

De modo geral, a descrição dos eventos e dos períodos do processo de adaptação estratégicas corrobora com o proposto por Pettigrew (1996), o qual alerta que as mudanças estratégicas são complexas e formadas por etapas, como a percepção, busca por eficiência, poder e capacidade de liderança.

No primeiro período analisado, houve um número reduzido de ações relacionadas às questões ambientais. Esse período caracterizou-se pela adoção de estratégias reativas e preocupação primária com a geração de lucros. A direção da empresa não demonstrou preocupação com as questões ambientais, procurando atender minimamente as exigências da legislação.

No segundo período, ocorreu um aumento das ações que envolvem as questões ambientais, além de se apresentarem de forma mais contínua e formulada. As ações empreendidas nesse período foram voltadas para o uso consciente dos recursos, com a manutenção dos resíduos gerados, destacando-se o aumento e o melhoramento dos processos de tratamentos dos resíduos e um controle sistemático dos seus índices. Infere-se que a empresa buscou melhorar sua imagem perante a comunidade, órgãos ambientais e governamentais, no intuito estratégico de conquistar novos mercados, e garantir a sustentabilidade (econômica, ambiental e social) do negócio.

A evolução ambiental da empresa no segundo período vem ao encontro do que foi descrito como ambientalismo empresarial ou estratégico (HOFFMAN, 1999) - que se refere à incorporação do meio ambiente pela agenda empresarial - uma vez que a direção geral da empresa procurou direcionar suas ações e práticas organizacionais diárias de forma proativa em relação às questões ambientais.

Não obstante, as atividades são vistas como oportunidades estratégicas que podem representar o diferencial competitivo da organização - posição esta não compreendida pelas empresas no início da inferência do meio ambiente sobre elas. Infere-se que desde os anos 1960, as empresas estão reavaliando as formas de gerir os problemas ambientais e desenvolvendo novas estratégias para lidar com seus desafios. Na década de 1970, as empresas viam sua relação com o meio ambiente como uma ameaça externa à lucratividade e às práticas empresariais estabelecidas (HOFFMAN, 2001). Contudo, ao longo das décadas, 
com a redefinição do papel do Estado, o fortalecimento das ONGs ambientalistas, as batalhas judiciais e legislativas em torno do meio ambiente e uma crescente atenção da opinião pública com relação ao tema, aconteceu um amplo processo de mudança institucional, que deu origem ao chamado ambientalismo empresarial (HOFFMAN, 1997), movimento este responsável por tornar o meio ambiente um componente importante na dinâmica das empresas.

Evidencia-se que a pressão social também exerceu papel importante no processo de adaptação estratégica da empresa. No modelo de Hoffman (1997, 2001), a institucionalização do ambientalismo empresarial é desencadeada pela ocorrência de uma série de eventos relacionados ao meio ambiente, tanto na esfera da sociedade quanto na das empresas, cuja percepção é mensurada pelo momento histórico e a dinâmica cultural, política e social que o envolve - suportando também, desse modo, o resultado da investigação deste estudo.

\section{Considerações}

O objetivo deste estudo consistiu em compreender e descrever o processo de adaptação estratégica em relação à gestão ambiental em uma agroindústria. Partiu-se da identificação das mudanças empreendidas no processo de adequação da organização e do levantamento e relato das principais ações e eventos que influenciaram as estratégias da empresa. A partir disso, identificaram-se as mudanças, procurando descrevê-las, de modo a perceber qual o cenário organizacional vivenciado pela empresa, identificando as causas que levaram a empresa a promover adaptações estratégicas.

Observou-se que ao longo da existência da empresa houve uma considerável evolução, com a inclusão e adaptação às variáveis ambientais. No primeiro momento (1997 a 2003) a empresa prendeu-se ao cumprimento das exigências da legislação, enquanto no segundo período (2004 a 2010) aumentaram as ações que envolviam as questões ambientais, momento em que a empresa assumiu suas responsabilidades gradativamente e de forma continuada, procurando conciliar e integrar as suas estratégias negociais com os interesses da sociedade, que abrange governo, clientes, fornecedores, enfim, toda sua cadeia de negócios.

Infere-se como fator fundamental dessa evolução a percepção e o envolvimento da alta administração, que foram imprescindíveis no processo de adaptação estratégica. Conclui-se que as mudanças da agroindústria em estudo, em todos os anos analisados, estavam relacionadas às compreensões e visões de negócio dos diretores e acionistas, sendo, no início, 
incipientes e depois como um processo de aprendizagem contínua. Assim, o processo de adaptação estratégica da empresa diz respeito à atitude inovadora dos empresários e administradores, que consideraram o meio ambiente em suas decisões e adotaram os princípios de sustentabilidade.

Cabe salientar que a implantação de projetos e programas que buscavam melhorar a atuação da empresa na questão ambiental, com o objetivo estratégico de melhorar sua imagem, possibilitou o aumento da produção e a conquista de novos mercados, o que converge com os benefícios estratégicos propostos por Donaire (2008) e a perspectiva de melhora da imagem, prevenção de acidentes ecológicos, satisfação da sociedade (comunidade local, governo, organizações e agências financiadoras) proposta por Alperstedt, Quintella e Souza (2010) e Moura (2008).

Finalmente, este estudo possui limitações quanto a seu escopo e processo, pois ele reflete os resultados de um estudo de caso único. Destarte, os resultados ora apresentados não devem ser tomados como certos. A aplicação de outros métodos de coleta e análise de dados a exemplo de pesquisas quantitativas ou qualitativas que envolvam índices de desempenho ambiental fica como sugestão para trabalhos futuros.

\section{Referências}

ALPERSTEDT, G. D.; QUINTELLA, R. H.; SOUZA, L. R. Estratégias de Gestão Ambiental e seus fatores determinantes: uma análise institucional. Revista de Administração de Empresas, v. 50, n. 2, p. 170-186, 2010.

BALDO, G. L et al. The carbon footprint measurement toolkit for the EU Ecolabel. International Journal of Life Cycle Assessment, v. 14, n. 7, p. 591-596, 2009.

BARBIERI, J. C. Gestão ambiental empresarial: conceitos, modelos e instrumentos. 2. ed. São Paulo: Saraiva, 2007.

BETHLERM, A. Estratégia empresarial: conceitos, processo e administração estratégica. 5. ed. São Paulo: Atlas, 2008. 
CAMARA, R. P. B. Desenvolvimento sustentável. In: ALBUQUERQUE, J. L. Gestão ambiental e responsabilidade social: conceitos, ferramentas e aplicações. São Paulo: Atlas, 2009.

CARROLL, A. B. Corporate social responsibility. Business and Society, Chicago, v. 38, n. 3, p. 268-295, 1999.

CUNHA, J. Adaptação estratégica e gestão ambiental: um estudo das mudanças organizacionais em uma indústria de fundição. Dissertação (Mestrado em Administração) Universidade do Vale do Itajaí, Biguaçú, 2008.

DIAS, R. Gestão ambiental: responsabilidade social e sustentabilidade. São Paulo: Atlas, 2009.

DONAIRE, D. Gestão ambiental na empresa. 2. ed. São Paulo: Atlas, 2008.

DRANOVE, D.; BESANKO, D.; SHANLEY, M.; SCHAEFER, S. A economia da estratégia. Tradução de Rachel Garcia Valdez. 3. ed. Porto Alegre: Artemed, 2006.

ELKINGTON, John. Canibais com garfo e faca. São Paulo: Makron Books, 2001.

GOMES, F. R. Difusão de inovações, estratégia e a inovação: o modelo DEI para os executivos. Rio de Janeiro: E-papers, 2007.

GUARNIERI, P. et al. Obtendo competitividade através da logística reversa: estudo de caso em uma madeireira. Journal of Technology Management \& Innovation, v. 1, n. 4, p. 121130, 2006.

HOFFMAN, A. J. From heresy to dogma: an institutional history of corporate environmentalism. San Francisco, Lexington Press, 1997.

HOFFMAN, A. J. Institutional evolution and change: environmentalism and the U.S. chemical industry. Academy of Management Journal, v. 42, n. 4, p. 351-371, 1999.

HOFFMAN, A. J. Linking organizational and field-level analyses - the diffusion of corporate environmental practice. Organization and Environment, v. 14, n. 2, p. 133-156, 2001. 
JOHNSON, G.; SCHOLES, K.; WHITTINGTON. Explorando a estratégia corporativa: textos e casos. Tradução de Renato A. Merker. 7. ed. Porto Alegre: Bookman, 2007.

MARTINS, J. P. S. Responsabilidade social coorporativa: como postura responsável compartilhada pode gerar valor. Campinas: Komedi, 2008.

MINTZBERG, H. et al. O processo da estratégia: conceitos, contextos e casos selecionados. 4. ed. Porto Alegre: Bookman, 2006.

MOORE, J. H.; KRAATZ, M. S. Governance Form and Organizational Adaptation: Lessons from the Savings and Loan Industry in the 1980s. Organization Science, v. 22, n. 4, p. 850868, Jul./Aug. 2011.

MOURA, L. A. A. Qualidade e gestão ambiental. 5. ed. São Paulo: Editora Juarez de Oliveira, 2008.

PETTIGREW, A. Context and action in the transformation of the firm. Journal of Management Studies, v. 24, n. 6, p. 649-670, 1987.

PORTER, M. E. Competição: estratégias competitivas essenciais. Tradução de Afonso Celso da Cunha Serra. 16. ed. Rio de Janeiro: Elsevier, 1999.

SEIFFERT, M. E. B. ISO 14001 Sistemas de Gestão Ambiental: implantação objetiva e econômica. 3. ed. São Paulo: Atlas, 2007.

TAO, B. Strategic capabilities: antecedents to mass customization. In: International Conference on Electronic Commerce and Business Intelligence Proceedings, p. 302-305, Beijing, 2009.

VIRANY, B.; TUSHMAN, M. L.; ROMANELLI, E. Executive succession and organization outcomes in turbulent environments - an organization learning approach. Organization Science, v. 3, n. 1, p. 72-91, 1992.

VIRVILAITE, R.; SEINAUSKIENE, B.; SESTOKIENE, G. The Link between Standardization/Adaptation of International Marketing Strategy and Company Performance. Inzinerine Ekonomika-Engineering Economics, v. 22, n. 1, p. 106-117, 2011. 
VITERBO JUNIOR, E. Sistema integrado de gestão ambiental: como implementar um sistema de gestão que atenda a norma ISO 14001 a partir de um sistema baseado na norma ISO 9000. São Paulo: Aquariana, 1998.

WINSEMIUS, P.; GUNTRAN, U. Mil tons de verde. Tradução de Durval Freire de Carvalho Olivieri. Salvador: Gráfica Santa Helena, 2004. 